\title{
Fungos em Bibliotecas: Frequência dos gêneros em livros e elaboração de teste para avaliação da biorreceptividade em papéis
}

Tese apresentada ao Instituto de Ciências Biomédicas da Universidade de São Paulo, para obtenção do Título de Doutor em Ciências.

Área de Concentração: Microbiologia

Orientador: Prof. Dr. Walderez Gambale 


\section{RESUMO}

REIS-MENEZES, A.A. Fungos em bibliotecas: frequência dos gêneros em livros e elaboração de teste para avaliação da biorreceptividade em papéis. $90 \mathrm{f}$. Tese (Doutorado em Microbiologia) - Instituto de Biomédicas, Universidade de São Paulo, São Paulo, 2009.

Em bibliotecas, a grande concentração de matéria orgânica, associada muitas vezes a uma climatização deficiente propicia um ambiente favorável ao crescimento fúngico. O principal objetivo deste trabalho é desenvolver um teste para detectar a biorreceptividade ao crescimento fúngico de papéis utilizados na confecção de livros. Em primeiro lugar, os gêneros de fungos foram amostrados nos períodos do inverno e verão, em seis bibliotecas da Universidade de São Paulo, três com climatização artificial e três sem climatização. Não houve diferença no número de gêneros de fungos encontrados entre as bibliotecas com e sem climatização artificial, mas o inverno mostrou maior diversidade que o verão. Com base nas amostragens foi selecionado o gênero Cladosporium para o teste, por ter sido o fungo mais frequente, e também os gêneros Aspergillus, Chaetomium e Trichoderma por terem sido fungos usados como micro-organismo em testes realizados em papel pela Standard Test Methods da Technical Association of the Pulp and Paper Industry (TAPPI). Os fungos foram inoculados em papel, composto apenas de celulose (papel referência) e também nos papéis comerciais couché, pólen e reciclado. Os papéis foram testados em câmaras úmidas com $95 \%$ e $100 \%$ de umidade relativa, a $25{ }^{\circ} \mathrm{C}$, por 30 dias. As análises foram feitas a partir da observação em microscópio estereoscópico do crescimento fúngico nos papéis e posterior determinação de alteração de cor utilizando-se um colorímetro. Nas câmaras com $100 \%$ de umidade, Aspergillus cresceu em $75 \%$ dos corpos-de-prova, Cladosporium em 74\%, Trichoderma em $72 \%$ e Chaetomium em 60\%. Em relação ao controle, a intensidade do crescimento foi estatisticamente significativa para o Cladosporium no papel couché, e para o Aspergillus no papel referência, enquanto Trichoderma e Chaetomium pouco alteram o papel. Nas condições do teste conclui-se que o melhor crescimento ocorreu com Cladosporium, na concentração de $10^{6}$ cél/mL e umidade relativa de $100 \%$.

Palavras-chave: Bibliotecas. Climatização. Fungos filamentosos. Papéis. Biorreceptividade. 


\begin{abstract}
REIS-MENEZES, A.A. Fungi in libraries: genera frequency in books and test development for evaluation of paper bioreceptivity. 90 p. Thesis (Ph.D. in Microbiology) - Instituto de Ciências Biomédicas, Universidade de São Paulo, São Paulo, 2009.

Libraries are very propitious environments for the growth of fungi. The great concentration of organic material available for these microorganisms, and often the lack of adequate ventilation or climate control, favors this situation. The main aim of this study is to develop a test to detect fungal growth bioreceptivity in papers used in books. Firstly, fungi genera where sampled in the summer and winter in six libraries of University of São Paulo, three with artificial climatization and three without. There was no difference in number between the libraries with and without artificial climatization but the diversity was higher in the winter than in the summer. The genus Cladosporium was selected for the test, based on the surveys and Aspergillus, Trichoderma and Chaetomium where also select because they were the fungi used in tests developed by the Standard Test Methods of Technical Association of the Pulp and Paper Industry (TAPPI). The fungi where inoculated in paper composed only by cellulose (reference paper) and also in the commercial papers, couché, polen, and recycled. The papers where tested in wet chambers with $95 \%$ and $100 \%$ of relative humidity, at $25{ }^{\circ} \mathrm{C}$ for 30 days. The analyses where performed from the observation of paper fungal growth in stereoscopic microscopic and detection of color alteration using a colorimeter. In the chambers with relative humidity of $100 \%$, Aspergillus grew in $75 \%$ of the papers, Cladosporium in $74 \%$, Trichoderma in $72 \%$ and Chaetomium in $60 \%$. In comparison with the control group, growth intensity was significantly higher for the Cladosporium in the couché paper, for Aspergillus in the reference while Trichoderma and Chaetomium hardly altered the paper. The conclusion based on the tests is that the highest growth occurred with Cladosporium, with $10^{6} \mathrm{cel} / \mathrm{mL}$ concentration and relative humidity of $100 \%$.
\end{abstract}

Key words: Libraries. Climatization. Airborne fungi. Papers. Bioreceptivity. 
INTRODUÇÃO 
Visto de uma perspectiva mais ampla, este trabalho pretende contribuir com novos conhecimentos a uma questão ainda pouco explorada no Brasil, diretamente relacionada à conservação do patrimônio cultural, especialmente daquele que usa o papel como substrato material.

A finalidade das bibliotecas, arquivos e museus é conservar e assegurar que o material ali depositado tenha durabilidade, possibilitando que a população tenha acesso ao conhecimento por meio das suas coleções de livros, documentos e objetos. Quando um objeto entra para o acervo de determinada entidade, todo esforço deve ser feito para que ele mantenha a sua integridade ao longo do tempo. Isso pode ser feito por meio do controle ambiental do local onde os objetos são guardados e exibidos. Desta forma, o patrimônio histórico, artístico e cultural em ambientes fechados pode ser preservado.

O controle ambiental é de fundamental importância dentro de uma biblioteca. As condições do ambiente interno têm que levar em conta não somente a preservação do acervo, mas também a garantia do conforto do público. Segundo King e Pearson (2001), a definição convencional de controle ambiental para preservação seria: "manutenção da luz, da temperatura e da umidade relativa, dentro de certos parâmetros, limitação rigorosa dos poluentes atmosféricos, inclusive, gases, partículas e esporos de fungos e eliminação de insetos e roedores." Para conseguir controlar todas essas variáveis, seria necessário um sistema de refrigeração ambiental de alta qualidade, o que seria quase impossível para muitos acervos.

Porém, ainda segundo King e Pearson (2001), a maioria dos autores considera que, de todas essas variáveis, o principal fator a ser controlado é a umidade relativa. A umidade relativa é diretamente proporcional à temperatura. Quando a temperatura aumenta, o ar é capaz de conter mais água, e quando ela diminui pode haver a formação de névoa e gotas de água (CRADDOCK, 2001). A suscetibilidade do material depende do seu teor de umidade que é definido pelo seu equilíbrio com a umidade do ambiente. A atividade de água (Aa) de um substrato é medida pela razão entre o vapor de pressão da água no substrato e a pressão da água pura. A água pura possui o valor máximo de atividade de água igual a 1 (SHIRAKAWA, 1999; FLORIAN, 1997). Singh (1994) afirma que valores inferiores a 0,65 de Aa não permitem o crescimento dos fungos, condição observada também por Pinzari et al. (2006) que mostra que o processo de degradação da celulose só pode ser iniciado com valores de atividade de água acima de 0,65. 
A umidade relativa do ar interno, além da relação com os objetos guardados em acervos, tem relação também com a umidade dos materiais de construção usados nos prédios que os abrigam. Principalmente em países tropicais, esses materiais podem começar a desprender água com o aumento da temperatura e, consequentemente, aumentar a umidade relativa interna (KING e PEARSON, 2001).

Até pouco tempo, acreditava-se que as condições ideais de temperatura e umidade só seriam mantidas por meio da climatização artificial do acervo. Porém, a ventilação natural promove a circulação do ar que, por sua vez, permite uma troca de umidade mais efetiva dos objetos com o ambiente (SCOTT, 2001). Muitas vezes a ventilação natural é a melhor escolha, principalmente em bibliotecas onde a manutenção do equipamento de refrigeração não é garantida e funciona de maneira intermitente.

Se as condições ambientais citadas acima não forem controladas, poderão ser observados vários processos de deterioração. Entre eles estão, a deterioração fotoquímica provocada pela luz natural ou artificial, a ação de insetos e roedores, danos físicos causados no material pela mudança brusca de umidade, crescimento de micro-organismos e outros (MENDES et al., 2001).

Os acervos de livros, em particular, são locais ideais para o crescimento de microorganismos, pois agrupam num mesmo espaço uma grande quantidade de matéria orgânica, como papel, cola de amido, couro e pano (NEVE et al., 2009; OGDEN, 1992; PARKER, 1987; HAINES e KOHLER, 1986). Os micro-organismos, devido à sua simplicidade morfológica, reprodução rápida e atividade fisiológica, possuem, em geral, grande adaptabilidade ao meio ambiente. Assim sendo, eles podem rapidamente desenvolver populações em diversos substratos, iniciando a sua decomposição (KOWALIK, 1980).

Dentre os micro-organismos, os fungos possuem um papel fundamental nos ciclos de decomposição e degradação da matéria orgânica na natureza. São organismos eucarióticos, aeróbicos e heterotróficos, e, como não possuem clorofila como os vegetais, necessitam de matéria orgânica que são incapazes de elaborar, sendo obrigados a viver como sapróbios, parasitas ou em simbiose (LACAZ et al., 2002).

A decomposição considerada benéfica ao homem é chamada de biodegradação e, quando ela se torna prejudicial, de biodeterioração. A biodeterioração pode ocorrer por diferentes processos: mecânicos, quando o material é danificado pelas forças físicas exercidas pelo organismo - por exemplo, os corpos de frutificação dos fungos - e químicos, quando o material é 
danificado por enzimas (celulases, hemicelulases, proteases, pectinases, enzimas lignolíticas) ou por metabólitos secundários liberados pelo fungo, que causam manchas no substrato (SINGH, 1994).

Segundo Singh (1994), há cinco fatores essenciais para o crescimento de fungos em qualquer substrato: fonte do inóculo, substrato ideal, água, oxigênio e temperatura adequada. Além desses, devem ser considerados também os níveis de $\mathrm{CO}_{2}, \mathrm{o} \mathrm{pH}$ e, em alguns casos, pressão, luz e outras formas de radiação. Dadas as condições ótimas, como temperatura entre $20{ }^{\circ} \mathrm{C}$ e $26{ }^{\circ} \mathrm{C}$, nutrientes, como a celulose dos livros, oxigênio, pH do substrato de ácido a neutro e água, os propágulos podem germinar e formar colônias em poucos dias (RAKOTONIRAINY e LAVÉDRINE, 2005; FLORIAN, 1997; YANG e JOHANNING, 1997; SINGH, 1994; GUSTAFSON et al., 1990; CRAIG, 1986). Os fungos, nesses ambientes, além de serem os maiores agentes de biodeterioração, são também importantes fontes de alérgenos, desencadeando alergias respiratórias em usuários atópicos (FLORIAN, 1997).

A presença de propágulos fúngicos no interior das bibliotecas frequentemente tem sua origem no ambiente exterior, mas o ambiente interno também pode se tornar uma fonte quando no local existirem alimentos, plantas, infiltrações ou mesmo aparelhos como os umidificadores. Os ambientes e estruturas de edificações promovem, ainda, microclimas e nichos ecológicos no seu ecossistema, que favorecem o estabelecimento, crescimento e proliferação de uma grande diversidade de fungos (FLORIAN, 1997). A variação da umidade relativa do ambiente e dos microambientes, como aqueles próximos a janelas, portas de porões, gavetas, caixas, prateleiras próximas ao chão, podem desencadear o crescimento fúngico, causando danos às decorações e materiais que neles se encontram, inclusive, às estruturas dos prédios (CLARKE et al., 1999; SINGH, 1994).

Além do ambiente exterior e do ambiente interno, é preciso levar em conta também os próprios materiais. Kowalik e Sandurska (1956) e Gallo (1993) compararam os propágulos de fungos do ar com aqueles que se desenvolviam em livros e gravuras antigas e verificaram que os fungos que cresciam no material estavam efetivamente no ar, mas nem sempre todos os que estavam no ar cresciam nesses materiais. Além do mais, embora as infestações fúngicas nos livros comecem na sua superfície, há casos em que ocorrem no seu interior, o que indica que podem ser o resultado do crescimento de propágulos fúngicos incorporados na matéria-prima 
durante a fabricação do papel ou durante o processo de limpeza e conservação (FLORIAN, 1997).

Além dos danos causados ao papel pelo típico crescimento fúngico na forma de colônias circulares ou como um pó espalhado sobre a superfície dos livros, existe um tipo de modificação do papel conhecido como foxing, que aparece frequentemente nos livros e é caracterizado por pequenas manchas amarronzadas. Apesar de todos os estudos desenvolvidos até hoje, esse fenômeno ainda não é bem entendido. A causa desse dano ao livro poderia ser de origem fúngica, mineral ou uma combinação de ambas (RAKOTONIRAINY et al., 2007).

O foxing biológico é causado pelo fungo que reage com o papel num processo lento, podendo estar associado aos sais de ferro presentes no papel. É um processo encontrado principalmente em livros antigos dos séculos XVI a XIX, mas que também já tem sido observado nos papéis modernos. É um sério problema de conservação, já que a mancha migra para páginas sucessivas, causando danos irreversíveis. O foxing mineral seria resultado da oxidação de metais contidos na impureza do papel durante o processo de manufatura (RAKOTONIRAINY et al., 2007; SARANTOPOULOU et al., 2003).

Apesar do verdadeiro papel dos fungos filamentosos no foxing ainda ser desconhecido, já se sabe, por meio de estudos tradicionais de cultura direta como também de análises mais modernas de caracterização biomolecular das cepas de amostras retiradas dessas manchas, que os fungos estão sempre presentes no foxing (ZOTTI et al., 2008; RAKOTONIRAINY et al., 2007; CORTE et al., 2003; SARANTOPOULOU et al., 2003).

Em 1997, Zyska, em revisão sobre fungos isolados em bibliotecas, apontava a falta de dados sobre o assunto na América do Sul. Atualmente, apesar da preocupação mundial com a qualidade do ar em ambientes internos, principalmente em relação a poluentes e microorganismos, no Brasil os trabalhos ainda são poucos e, na maioria dos casos, relacionados a edifícios de escritório climatizados artificialmente (DEGOBBI e GAMBALE, 2008; GRAUDENZ et al., 2004, 2002).

Em relação a fungos em ambientes de bibliotecas, destaca-se, no Brasil, o trabalho de Gambale et al. (1993), realizado com o objetivo de verificar a sensibilização a fungos em funcionários de 28 bibliotecas da Universidade de São Paulo. Nesse trabalho, os autores isolaram fungos do ar ambiente e de livros deteriorados. Os fungos mais frequentemente isolados foram: Acremonium, Alternaria, Aspergillus, Aureobasidium, Cladosporium, Curvularia, Epicoccum, 
Fusarium, Geotrichium, Helminthosporium, Monascus, Mycelia Sterilia (fungo não esporulante), Neurospora, Nigrospora, Penicillium, Phoma, Rhizopus, Rhodotorula e Trichoderma. Os fungos mais frequentes em livros deteriorados foram: Aspergillus, Cladosporium, Penicillium e Trichoderma.

Em outros países, trabalhos associando fungos presentes no ar e nos livros em bibliotecas também são escassos, destacando-se o trabalho de Burge et al. (1980) realizado em 11 bibliotecas da Universidade de Michigan. Nesse trabalho, os autores verificaram que os gêneros encontrados no interior dos prédios eram similares àqueles encontrados no ambiente externo. Os gêneros mais frequentes foram: Alternaria, Arthrinium, Aspergillus, Cladosporium, Epicoccum, Fusarium, Paecilomyces, Penicillium, Pithomyces, Rhinocladiella, Sporothrix, Trichoderma e Tritirachium. Para verificar quais os fungos poderiam utilizar o livro como substrato para se desenvolver, os autores inocularam os fungos isolados em um substrato composto de ágar e papel filtro. Os gêneros que utilizaram a celulose como fonte de nutriente foram: Alternaria, Aspergillus, Cladosporium, Epicoccum, Fusarium, Pithomyces e Trichoderma e os que mais produziram conídios nesse substrato foram Alternaria, Epicoccum e Pithomyces. Os mesmos gêneros foram isolados por Florian (2000) em livros, acrescentando-se apenas Chaetomium, Monilia, Mucor e Stachybotrys.

O foco deste trabalho é verificar a resistência de papéis usados atualmente na impressão de livros às infestações por fungos. Atualmente existe uma grande gama de papéis fabricados para os mais diversos fins, cuja composição e qualidade foram variando ao longo do tempo. A maioria dos historiadores atribui a Ts'ai Lum (105 D.C.) a descoberta do papel por meio da polpação de redes de pesca e trapos, e, mais tarde, de fibras de vegetais. Os exemplares que chegaram até nossos dias provam que o papel feito pelos antigos chineses era de alta qualidade. As fibras desses papéis antigos eram longas e lineares, e apenas um composto, a cola animal, era utilizado na sua colagem (LIMA et al., 1988).

À medida que as técnicas de escrita e impressão foram sendo mecanizadas, houve um aumento gradual na demanda de papel no mundo, e, consequentemente, escassez de matériaprima, como os trapos e fibras de linho e de algodão. Novas fontes de celulose começaram, então, a ser estudadas, e a madeira mostrou-se uma excelente matéria-prima (KUAN et al., 1988).

A madeira é constituída basicamente por celulose, hemicelulose, lignina e constituintes menores. A concentração dessas substâncias varia conforme a espécie vegetal, mas pode-se dizer 
que aproximadamente 50\% seriam de celulose, $20 \%$ hemicelulose, $15-35 \%$ de lignina e até $10 \%$ de constituintes menores (D’ALMEIDA, 1988).

A celulose, que é o principal componente das paredes das células vegetais, é um polissacarídeo linear constituído por um único tipo de açúcar (D-glicose). O grau de polimerização (número de monômeros) da celulose proveniente de madeira, como o eucalipto, chega a 10.000 unidades, enquanto que a celulose de plantas, como o algodão, possui até 15.000 unidades (LAGUARDIA et al., 2005). Isso permite classificar as fibras vegetais, do ponto de vista da produção de papel, em fibras curtas e longas.

A hemicelulose é um polímero ramificado de cadeia curta, sendo um polissacarídeo composto de diferentes tipos de unidades de açúcar (D-xilose, D-manose, D-glicose, L-arabinose etc). Ela confere características importantes às pastas celulósicas, tais como redução no tempo de refino e aumento da flexibilidade das fibras (D’ALMEIDA, 1988).

A lignina é um polímero amorfo, de composição química complexa, pois pode ser composta por uma mistura de substâncias orgânicas. Ela confere firmeza e rigidez ao conjunto de fibras de celulose. As ligninas das paredes celulares dos vegetais estão sempre associadas às hemiceluloses (D'ALMEIDA, 1988).

Os constituintes menores são compostos orgânicos e inorgânicos, que conferem determinadas características às plantas, como cor, sabor, cheiro, resistência ao apodrecimento etc. Essas características variam entre as espécies de plantas, assim como com a idade e região de ocorrência do vegetal (D'ALMEIDA, 1988).

As fibras de madeira de maior importância econômica são as de árvores do grupo das dicotiledôneas arbóreas (Angiospermae) e das coníferas (Gymnospermae). Embora a maior parte das fibras tenha sua origem no tronco das árvores (parte lenhosa), elas também podem vir das folhas, como o sisal, e dos frutos, como o algodão (KOGA, 1988).

No Brasil, a madeira mais utilizada para a fabricação do papel é o eucalipto, proveniente de plantações mantidas pelas fábricas. O eucalipto, devido ao seu rápido crescimento, foi uma espécie escolhida inicialmente para reflorestamento de áreas degradadas (LIMA et al., 1988). As espécies atualmente utilizadas foram trazidas principalmente da Austrália e Tasmânia e introduzidas no Brasil há cerca de 150 anos. 
O papel produzido a partir da madeira possui uma coloração escura e contém muito material não-desintegrado. A pesquisa de novas técnicas, na busca de papéis mais claros, resistentes e com boas qualidades de impressão, culminou com diferentes métodos de polpação e branqueamento das pastas celulósicas (LIMA et al., 1988).

O processo de polpação, ou seja, de separação das fibras da madeira, pode ser feito utilizando-se energia química e/ou mecânica. No processo mecânico, forças de cisalhamento rompem as ligações das fibras e a pasta resultante contém fibras inteiras, feixes de fibras e fibras danificadas. Na polpação química, as fibras apresentam-se menos danificadas e observa-se a remoção de lignina e hemicelulose. As pastas celulósicas são classificadas, então, a partir do seu processo de fabricação e podem ser separadas em pasta química, semiquímica, mecânica, branqueada e não-branqueada. No Brasil, a maior parte da pasta celulósica é obtida por meio da polpação química, que pode ser dividida basicamente em dois grandes processos, o Kraft (Sulfato), conhecido como polpação química alcalina, e o processo sulfito. Atualmente a maior parte dos papéis é produzida pelo processo kraft (ASSUMPÇÃO et al., 1988).

O branqueamento consiste em remover a lignina ou os derivados da lignina que ainda permaneceram na pasta após o processo de polpação. Trata-se de um processo físico-químico que tem por objetivo melhorar a alvura, limpeza e pureza química das pastas celulósicas. De modo geral, os mecanismos do branqueamento podem ser divididos em: difusão do reagente em solução até a superfície da fibra, absorção do reagente pela fibra, reação química, dessorção do reagente excedente da fibra e difusão de produtos de reação para fora da fibra. Resumindo, o branqueamento se inicia com a adição de um reagente e termina com a remoção dos produtos da reação (DANILAS, 1988).

A folha de papel contendo apenas celulose é porosa, pouco resistente, possui uma superfície mais rugosa e a cor não é satisfatória, segundo os padrões exigidos pelo mercado papeleiro. Para melhorar a qualidade do papel, são adicionados produtos químicos que podem eliminar esses problemas. Alguns dos principais produtos são agentes de colagem, cargas (pigmentos), corantes, adesivos para melhorar as propriedades mecânicas do papel em condições secas e úmidas, aditivos etc. (KUAN et al., 1988).

A colagem confere resistência à penetração de líquidos e é usada em papéis para escrever, imprimir, embalar etc. Já os papéis não-colados, como papéis de seda, mata-borrão, lenço, toalha e sanitários, são fabricados para ter uma rápida absorção de líquidos. Existem dois tipos de 
colagem, a interna e a superficial. Na colagem interna, são usados produtos como colas à base de breu, silicones, polietilenos, perfluorcarbonetos e colas sintéticas, adicionados durante a preparação da massa. A colagem superficial, além de evitar a penetração de líquidos por meio da aplicação de substâncias que formam películas, melhora a aparência do papel. Os materiais mais usados são cola animal, gelatina, álcool polivinílico, alginato de sódio, carboximetil celulose (CMC) e amidos (CAPPITELLI e SORLINI, 2005; KUAN e BENAZZI, 1988; PIRES et al., 1988).

As cargas minerais promovem maior uniformidade ao papel, melhorando características como alvura, lisura, opacidade e a qualidade de impressão. Os pigmentos mais utilizados para esse fim são dióxido de titânio, caulim, carbonato de cálcio e talco.

A cor do papel pode ser alterada por meio de corantes e pigmentos. Os corantes são os mais utilizados por serem mais solúveis, por terem maior poder de coloração, por possuírem maior gama de tonalidades e por não alterarem as propriedades do papel. Os corantes podem ser ácidos, básicos, diretos (mais complexos) e de enxofre. Os pigmentos são sólidos e insolúveis em água, podem ser naturais ou sintéticos, orgânicos e inorgânicos. De modo geral, os pigmentos coloridos são menos usados por não conferirem coloração uniforme ao papel (CAPPITELLI e SORLINI, 2005; KUAN e BENAZZI, 1988; PIRES et al., 1988).

Os adesivos são utilizados como fixadores do pigmento a ser usado como revestimento da folha de papel. Eles também são classificados em naturais e sintéticos. Aos naturais pertence o amido, a caseína e as colas animais (gelatina). Os sintéticos seriam os acetatos polivinílicos, látex estireno-butadieno, acrílicos etc. O revestimento é um passo a mais no aumento da qualidade superficial do papel, e pode ser dividido em revestimento para impressão (melhor qualidade de impressão), decorativos (aparência) e funcionais (melhorar uma propriedade característica, como resistência à umidade) (KUAN e BENAZZI, 1988).

Os aditivos consistem em substâncias indispensáveis ao processo de manufatura do papel, mas que não podem estar presentes no produto final em grandes concentrações. Eles são substâncias usadas como dispersantes, controladores de espuma, modificadores de viscosidade, lubrificantes, agentes preservativos e outros (KUAN e BENAZZI, 1988).

A Associação Brasileira de Celulose e Papel (BRACELPA) separa os tipos de papel em: papel para imprensa; para imprimir e escrever; para embalagem; para fins sanitários; cartão e outros fins. O interesse deste trabalho recai sobre os papéis para impressão, que são divididos em: 
- bíblia - papel fabricado com pasta química branqueada, com alto teor de carga mineral e elevada opacidade;

- bouffant - o papel de primeira é fabricado com pasta química branqueada, não colado, alta carga mineral, bem encorpado e absorvente. O bouffant de segunda contém pasta mecânica;

- couché - é um papel de alta qualidade, revestido em sua superfície com cargas minerais;

- imprensa - papel fabricado com pasta mecânica ou mecano-química, com ou sem colagem, de gramatura fixa em 45 a $56 \mathrm{~g} / \mathrm{m}^{2}$;

- jornal - similar ao de imprensa, porém sem limitação de gramatura;

- monolúcido - fabricado com pasta química branqueada com brilho em uma das faces. O monolúcido de segunda contém pasta mecânica;

- offset - fabricado com pasta química branqueada com elevada resistência da superfície.

Os papéis utilizados como corpos-de-prova nos testes foram: o papel de referência produzidos pelo Instituto de Pesquisa Tecnológicas de São Paulo (IPT) e os papéis comerciais Couchê Matte Fosco, Pólen (offset) e Reciclado.

O papel reciclado, de acordo com a BRACELPA, não se enquadra em nenhuma das categorias citadas acima. Entretanto, é um papel cada vez mais utilizado para impressão. Não existe, seja no Brasil ou no exterior, regulamentação sobre o percentual de papel pós-consumo a ser usado para que o papel seja considerado reciclado. Cada papel, conforme a sua utilização precisa obedecer a determinadas especificações técnicas, e essas especificações podem ficar comprometidas em função da proporção de fibras recicladas e da fadiga dessas fibras. Isso, consequentemente, interfere nas propriedades físicas e mecânicas do papel. Existem situações de uso nas quais o papel pode ser composto de $100 \%$ de aparas pós-consumo, como alguns papéis higiênicos e papéis-toalha. Quando falamos em papéis de imprimir e escrever, que necessitam de resistência superficial, ausência de poeira, opacidade e outras propriedades físico-químicas, os percentuais pós e pré-consumo variam segundo a receita de cada fabricante.

As aparas passam por diversos processos de limpeza, tanto mecânicos como químicos, nos quais são usadas máquinas próprias para cada função. A primeira etapa é a retirada das impurezas mais pesadas, depois vem a retirada de materiais proibitivos, seguido da separação das 
fibras (fracionamento), que permite separar as fibras longas das curtas. Por fim é feito o destintamento. A pasta celulósica resultante também pode ser branqueada.

A degradação biológica da celulose é resultante de uma hidrólise enzimática catalisada pela enzima celulase. Nesse tipo de degradação microbiológica, existe perda de resistência da celulose, mas ela não é acompanhada por uma grande diminuição da massa e do grau de polimerização (D’ALMEIDA, 1988).

Existem, ainda, enzimas não-hidrolíticas envolvidas na degradação da celulose, como a oxidase e a celobiose desidrogenase $(\mathrm{CDH})$, que produzem peróxido de hidrogênio. O interesse pela $\mathrm{CDH}$ tem crescido muito nos últimos anos, principalmente pelo seu potencial de uso em grande escala pela indústria de polpa e papel (BAMINGER, 1999).

A CDH é produzida por fungos basidiomicetos degradadores de madeira, e também por diversos gêneros de fungos filamentosos como Cladosporium, Chaetomium, Monilia, Sporotrichum, Stachybotrys e Trichoderma (VASIL'CHENKO et al., 2005; GHAHFAROKHI et al., 2004; MANSFIELD et al., 1997).

Entre os outros tipos de degradação que a celulose pode sofrer, os mais importantes são a degradação pela luz e a por efeito térmico. Os efeitos nocivos ocorrem especialmente na faixa ultravioleta e em temperaturas acima de $140{ }^{\circ} \mathrm{C}$. Assim, as reações de degradação do papel nessas condições são aceleradas, principalmente na presença de ar, umidade e acidez residual (FLORIAN, 1997).

Os temas relacionados à conservação do patrimônio cultural, tais como a preservação de acervos, o controle ambiental, os materiais usados na construção dos prédios onde serão abrigados os acervos, o controle de pragas, a poluição do ar interior e o efeito da iluminação sobre os objetos, são debatidos regularmente no exterior e os seus resultados são divulgados por meio de uma vasta produção de literatura sobre o assunto. Segundo Mendes et al. (2001), no Brasil essa produção ainda é muito tímida e muitas vezes o acesso à informação fica restrito às principais cidades brasileiras, sendo pequena a repercussão nacional sobre as ações que trariam melhorias à manutenção de acervos.

Como se pode verificar pelo exposto, os trabalhos no Brasil sobre o tema são escassos. O papel utilizado na confecção de livros continua sendo, no entanto, substrato para crescimento de fungos e conseqüente deterioração, na dependência de fatores climáticos peculiares de cada região. 
A escolha de bibliotecas climatizadas e não climatizadas vem da preocupação cada vez maior com a qualidade do ar interno dos ambientes climatizados artificialmente. A Agência Nacional de Vigilância Sanitária (ANVISA), através da Resolução - RE N 176, 24 de outubro de 2000, regulamenta sobre as propriedades físicas, químicas e biológicas que devem prevalecer nos ambientes climatizados para que eles não promovam riscos à saúde dos ocupantes. Os fungos isolados nos livros são aqueles presentes no ar das bibliotecas com e sem climatização artificial. Isto permite que seja feita uma comparação da diversidade fúngica entre esses dois ambientes, possibilitando a identificação do fungo mais frequente e consequentemente do micro-organismo que poderia ser usado nos testes.

Este trabalho tem como objetivo propor um novo teste laboratorial para detectar a biorreceptividade ao crescimento fúngico de papéis utilizados na confecção de livros, adicionando mudanças significativas para uma melhor avaliação da qualidade de papel, levandose em conta as condições existentes no Brasil. A partir do protocolo da Standard Test Methods da Technical Association of the Pulp and Paper Industry (TAPPI), associação responsável pela padronização de testes em papéis, foram realizados novas análises com o intuito de fornecer subsídios ao setor produtivo na busca de material resistente à contaminação fúngica. 
CONCLUSÕES 


\section{AMOSTRAGEM DE FUNGOS}

- Não houve diferença na diversidade de gêneros fúngicos entre bibliotecas com e sem climatização artificial.

- Houve maior diversidade fúngica no inverno em relação ao verão.

- Clasdoporium, Alternaria, Arthrinium, Curvularia, Epicoccum, Monascus, Nigrospora e Rhizopus foram os gêneros mais frequentemente isolados dos livros no inverno e Aspergillus, Fusarium e Fungos não esporulantes no verão.

- Cladosporium, Monascus, e Trichoderma foram mais frequentes nos livros das bibliotecas sem climatização e Paecilomyces foi mais frequente nas bibliotecas com climatização artificial.

\section{TESTES DE AVALIAÇÃO DA BIORRECEPTIVIDADE}

- A câmara úmida deve ser colocada a uma temperatura de $25{ }^{\circ} \mathrm{C}$ e o ambiente interno das câmaras de teste deve ter umidade relativa de $100 \%$.

- O fungo que mostrou as melhores condições de crescimento foi Cladosporium e, portanto, deve ser utilizado como inóculo nos testes de biorreceptividade.

- A concentração do inóculo que provocou as maiores alterações no papel foi $10^{6}$ células/mL que, portanto, deve ser utilizada nos testes.

- A análise da alteração de cor do papel pelo método de colorimetria mostrou ser uma ferramenta importante na avaliação da biorreceptividade.

Portanto, para avaliar a biorreceptividade dos papéis, deve ser utilizada uma câmara úmida com $100 \%$ de umidade, temperatura de $25{ }^{\circ} \mathrm{C}$ e um inóculo de $10^{6}$ cél $/ \mathrm{mL}$ de Cladosporium. 


\section{REFERÊNCIAS BIBLIOGRÁFICAS ${ }^{*}$}

ADAMO, M.; MAGAUDDA, G.; OMARINI, S. Biological measurement of damage occurring to the inner structure of paper after gamma irradiation. Restaurator, v.28, p.39-46, 2007.

AGÊNCIA NACIONAL DE VIGILÂNCIA SANITÁRIA. Resolução - RE $\mathbf{N}^{\circ} \mathbf{1 7 6}, 24$ de outubro de 2000. Disponível em: <http//e-legis.anvisa.gov.br/leisref/public/showAct.php? $\mathrm{id}=7377 \&$ word=>. Acesso em: 28 fev. 2009.

ASSUMPÇÃO, R.M.V.; PINHO, M.R.R.; CAHEN, R.; PHILIPP, P. Polpação Química. In: PHILIPP, P.; D'ALMEIDA M.L.O. (Ed.). Celulose e Papel - Tecnologia da fabricação da pasta celulósica. 2. ed. São Paulo: IPT/SENAI, 1988. v.1, p. 169-319.

BAMINGER, U.; NIDETZKY, B.; KULBE, K.D.; HALTRICH, D. A simple assay for measuring cellobiose dehydrogenase activity in the presence of laccase. Journal of Microbiological Methods, v.35, n.3, p.253-259, 1999.

BORTOLETTO, M.E. Contaminações fúngicas em ambientes fechados: O caso da biblioteca de Manguinhos. Revista Brasindoor, v.II, n.11, p. 4-16, 1998.

ASSOCIAÇÃO BRASILEIRA DE CELULOSE E PAPEL. Tipos de papel. Disponível em: <http://www.bracelpa.org.br/bra/saibamais/tipos/index.html>. Acesso em: 10 fev. 2009.

BUCK, N.; GAMBALE, V. Microbiota fúngica anemófila da cidade de Presidente Prudente, Estado de São Paulo, Brasil. Revista de Microbiologia, v.16, n.1, p. 9-14, 1985.

BUGAJER, S. Utilização de aparas e papéis velhos. In: PHILIPP, P.; D’ALMEIDA M.L.O. (Ed.). Celulose e Papel - Tecnologia da fabricação da pasta celulósica. 2. ed. São Paulo: IPT/SENAI, 1988. v.2, p. 797-818.

BURGE, H.P.; BOISE, J.R.; SOLOMON, W.R.; BANDERA, E. Fungi in libraries: an aerometric survey. Mycopathologia, v.64, n.2, p. 67-72, 1980.

CAPPITELLI, F.; SORLINI, C. From papyrus to ompact-disc: the microbiol deterioration of documentary heritage. Critical Reviews in Microbiology, v.31, n.1, p.1-10, 2005.

CASSAR, M. Os museus do Reino Unido: abordagem estratégica da gestão ambiental. In: MENDES, M.; DA SILVEIRA, L.; BEVILAQUA, F.; BAPTISTA, A.C.N. (Org.). Conservação - Conceitos e práticas. Tradução de Vera Ribeiro. Rio de janeiro: UFRJ, 2001. p.305-319.

\footnotetext{
*De acordo com: ASSOCIAÇÃO BRASILEIRA DE NORMAS TÉCNICAS. NBR 6023: Informação e documentação: referências: elaboração. Rio de Janeiro, 2002.
} 
COMMISSION INTERNATIONALEDE L'ECLAIRAGE. Color Systems. Available from: $<$ http://www.byk.com/instruments/applications/solid_color_3_US.php $>$. Acesso em: 28 Fev. 2009.

CORTE, A.M.; FERRONI, A.; SALVO, V.S. Isolation of fungal species from test samples and maps damaged by foxing, and correlation between these species and the environment. International Biodeterioration and Biodegradation, v.51, n.3, p.167-173, 2003.

CRADDOCK, A.B. Controle de temperatura e umidade em acervos pequenos. In: MENDES, M.; DA SILVEIRA, L.; BEVILAQUA, F.; BAPTISTA, A.C.N. (Org.). Conservação - Conceitos e práticas. Tradução de Vera Ribeiro. Rio de janeiro: UFRJ, 2001. p.65-82.

CLARKE, J.A.; JOHNSTONE, C.M.; KELLY, N.J.; McLEAN, R.C.; ANDERSON, J.A.; ROWAN, N.J.; SMITH, J.E. A technique for the prediction of the conditions leading to mould growth in buildings. Building and Environment, v.34, p. 515-521, 1999.

CRAIG, R. Alternative approaches to the treatment of mould biodeterioration- an international problem. The Paper Conservator, v.10, p. 27-30, 1986.

D’ALMEIDA, M.L.O. Composição Química dos materiais ligno-celulósicos. In: PHILIPP, P.; D'ALMEIDA, M.L.O. (Ed.). Celulose e Papel - Tecnologia da fabricação da pasta celulósica. 2. ed. São Paulo: IPT/SENAI, 1988. v.1, p. 44-105.

DANILAS, R.M. Branqueamento de pastas celulósicas. In: PHILIPP, P.; D’ALMEIDA, M.L.O. (Ed.). Celulose e Papel - Tecnologia da fabricação da pasta celulósica. 2. ed. São Paulo: IPT/SENAI, 1988. v.1, p. 427-512.

DEGOBBI, C.M.; GAMBALE, W. Síndrome dos Edifícios Doentes: Aspectos microbiológicos, qualidade de ar em ambientes interiores e legislação brasileira. Revista Microbiologia in foco, n.4, p.19-32, 2008.

DUTRA, L.M.M. Microbiota fúngica em ambientes climatizados artificialmente antes e após a higienização. 72 f. Dissertação (Mestrado em Microbiologia) - Instituto de Ciências Biomédicas, Universidade de São Paulo, São Paulo, 2002.

FARIA, A. Aspectos ecológicos e clínicos da flora micótica anemófila de Belo Horizonte. 81 f. Tese (Doutorado) - Faculdade de Medicina, Universidade de Minas Gerais, Belo Horizonte, 1967.

FLORIAN, M-L. E. Aseptic Technique: a goal to strive for in collection recovery of moldy archival materials and artfacts. Journal of the American Institute for Conservation, v.39, p. 107-105, 2000.

FLORIAN, M-L. E. Heritage Eaters - Insects \& fungi in heritage collections. Londres: James \& James Science Publishers, 1997. 
GALLO, F. Aerobiological research and problems in libraries. Aerobiologia, v. 9, p.117-130, 1993.

GAMBALE, W.; CROCE, J.; COSTA-MANSO, E.; CROCE, M.; SALES, M. Library fungi at the University of São Paulo and their relationship with respiratory allergy. Journal of Investigational Allergology and Clinical Immunology, v.3, n.1, p. 45-50, 1993.

GAMBALE, W.; PURCHIO, A.; PAULA, C.R. Influência de fatores abióticos na dispersão aérea de fungos na cidade de São Paulo, Brasil. Revista de Microbiologia, v.14, p.204-214, 1983.

GAMBALE, W.; PURCHIO, A.; PAULA, C.R. Periodicidade diária de fungos anemófilos na cidade de São Paulo, Brasil. Revista de Microbiologia, v.12, n.4, p.176-181, 1981.

GAMBALE, W.; PURCHIO, A.; CROCE, J. Flora fúngica anemófila da grande São Paulo. Revista de Microbiologia, v.8, n.3, p. 74-9, 1977.

GHAHFAROKHI, M.S.; FAZLI, A.; LOTFI, A.; ABYANEH, M.R. Cellobiose dehydrogenase production by the genus Cladosporium. Iranian Biomedical Journal, v.8, n.2, p.107-111, 2004.

GOMPERTZ, O.F.; GAMBALE, W.; PAULA, C.R.; CORRÊA, B. Alergia e Fungo. In: TRABULSI, L.R.; ALTERTHUM, F. Microbiologia. 4. ed. São Paulo: Atheneu, 2005. p.501503.

GRAUDENZ, G.S.; KALIL, J.; SALDIVA, P.H.; LATORRE, M. do R.D.O.; MORATOCASTRO, F.F. Decreased Respiratory Symptoms After Intervention in Artificially Ventilated Offices in São Paulo, Brazil. CHEST, v.125, n.1, p. 326-329, 2004.

GRAUDENZ, G.S.; KALIL, J.; SALDIVA, P.H.; GAMBALE, W.; LATORRE, M. do R.D.O; MORATO-CASTRO, F.F. Upper Respiratory Symptoms Associated With Aging of the Ventilation System in Artificially Ventilated Offices in São Paulo, Brazil. CHEST, v.122, n.2, p.729-735, 2002.

GUSTAFSON, R.A.; MODARESI, I.R.; HAMPTON, G.V.; CHEPESIUK, R.J.; KELLEY, G.A. Fungicidal efficacy of selected chemicals in thymol cabinets. Journal of the American Institute for Conservation, v.29, n.2, p.153-168, 1990.

HAINES, J.H.; KOHLER, S.A. An evaluation of ortho-phenyl phenol as a fungicidal fumigant for archives and libraries. Journal of the American Institute for Conservation, v.25, n.1, p. 49$55,1986$.

HOOG, G.S.; GUARRO, J.; GENÉ, J.; FIGUERAS, M.J. (Ed.). Atlas of clinical Fungi. Utrecht: CBS, 1995. 720p.

JONES, B.L.; COOKSON, J.T. Natural atmospheric microbial conditions in a typical suburban area. Applied and Environmental Microbiology, v.45, n.3, p. 919-934, 1983. 
KING, S.; PEARSON, C. CASSAR, M. Controle ambiental para instituições culturais: planejamento adequado e uso de tecnologias alternativas. In: MENDES, M.; DA SILVEIRA, L.; BEVILAQUA, F.; BAPTISTA, A.C.N. (Org.). Conservação - Conceitos e práticas. Tradução de Vera Ribeiro. Rio de janeiro: UFRJ, 2001, p.41-64.

KOGA, M.E.T. Matérias-primas fibrosas. In : PHILIPP, P.; D’ALMEIDA M.L.O. (Ed.). Celulose e Papel - Tecnologia da fabricação da pasta celulósica. 2. ed. São Paulo: IPT/SENAI, 1988. v.1, p. 15-40.

KOWALIK, R. Microbiodeterioration of Library Materials. Restaurator, v.4, n.2, p.99-114, 1980.

KOWALIK, R.; SADURSKA, I. Microorganisms destroying paper, leather and wax seals present in the air of archives. Acta Microbiologica Polonica, v.5, n.2, p.277-284, 1956.

KUAN, G.S.S.; BENAZZI, R.C.; BERGMAN, S. Matérias-primas. In: PHILIPP, P.; D’ALMEIDA M.L.O. (Ed.).Celulose e Papel - Tecnologia da fabricação da pasta celulósica. 2. ed. São Paulo: IPT/SENAI, 1988. v.2, p. 561-582.

KUAN, G.S.S.; BENAZZI, R.C. Colagem superficial e revestimento. In: PHILIPP, P.; D’ALMEIDA M.L.O. (Ed.). Celulose e Papel - Tecnologia da fabricação da pasta celulósica. 2. ed. São Paulo: IPT/SENAI, 1988. v.2, p. 757-796.

LACAZ, C. da S.; PORTO, E.; MARTINS, J.E.C.; HEINS-VACCARI, E.M.; MELO, N.T. de. Tratado de micologia médica . São Paulo: Sarvier, 2002.

LACAZ, C. da S.; PORTO, E.; MARTINS, J.E.C.; HEINS-VACCARI, E.M.; MELO, N.T. de. Guia para Identificação - Fungos, actinomicetos e algas de interesse médico. São Paulo: Sarvier, 1998. 445p.

LAGUARDIA, L.; VASSALLO, E.; CAPPITELlI, F.; MESTO, E.; CREMONA, A.; SORLINI, C.; BONIZZONI, G. Investigation of the effects of plasma treatments on biodeteriorated ancient paper. Applied Surface Science, v.252, n.4, p.1159-1166, 2005.

LIMA, A.F.; RODÉS, L.; PHILIPP, P. Alguns dados da história do papel. In: PHILIPP, P.; D’ALMEIDA M.L.O. (Ed.). Celulose e Papel - Tecnologia da fabricação da pasta celulósica. 2. ed. São Paulo: IPT/SENAI, 1988. v.1, p. 1-13.

MACHADO, G.M.R. Fungos anemófilos de áreas do grande Recife- Estudo qualitativo e quantitativo. 47 f. Tese (Mestrado) - Centro de Ciências da Saúde, Universidade Federal de Pernambuco, São Paulo, 1999.

MANSFIELD, S.D.; de JONG, E.; SADDLER, J.N. Cellobiose Dehydrogenase, an Active Agent in Cellulose Depolymerization. Applied and Environmental Microbiology, v.63, n.10, p. 38043809, 1997. 
MENDES, M.; da SILVEIRA, L.; BEVILAQUA, F.; BAPTISTA, A.C.N. (Org.). Conservação - Conceitos e práticas. Tradução de Vera Ribeiro. Rio de janeiro: UFRJ, 2001. 336 p.

MENEZES, E.A.; ALCANFOR, A.C.; CUNHA, F.A. Fungos anemófilos na sala de periódicos da biblioteca de ciências da saúde da Universidade do Ceará. Revista Brasileira de Análises Clínicas, v.38, n.3, p.155-158, 2006.

MEZZARI, A.; PERIN, C.; SANTOS JÚNIOR, S.A.; BERND, L.A.G. Airborne fungi in the city of Porto Alegre, Rio Grande do Sul, Brasil. Revista do Instituto de Medicina Tropical de São Paulo, v.44, n.5, p.269-272, 2002.

MILES, A.A.; MISRA, S.S.; IRWIN, J.O. The estimation of the bactericidal power of the blood. The Journal of Hygiene, v.38, p.732-749, 1938.

MORROW, M.B.; MEYER, G.H.; PRINCE, H.E. A summary of airborne mold surveys. Annals of Allergy, v.22, p. 575-587, 1964.

NEVE, E.R.; SCHÄFER, S.; PHILLIPS, A.; CANEJO, J.; MACEDO, M.F. Antifungal effect of different methyl and propyl paraben mixtures on the treatment of paper biodeterioration. International Biodeterioration \& Biodegradation, v.63, p.267-272, 2009.

OGDEN, S. (Ed.). Protecting books and paper against mold. In: Preservation of library and archival materials: a manual. Andover, MA: Northeast Document Conservation Center, 1992.

PARKER, T.A. Integrated pest management for libraries. In: SMITH, M.A. (Ed.). Preservation of library materials. Munich: K.G. Saur, 1987. p.103-123.

PEARSON, C. Preservação de acervos em países tropicais. In: MENDES, M.; DA SILVEIRA, L.; BEVILAQUA, F.; BAPTISTA, A.C.N. (Org.). Conservação - Conceitos e práticas. Tradução de Vera Ribeiro. Rio de janeiro: UFRJ, 2001, p.35-40.

PINZARI, F.; PASQUARIELLO, G.; DE MICO, A. Biodeterioration of paper: A SEM study of fungal spoilage reproduced under controlled conditions. Macromolecular Symposia, v.238, p. 57-66, 2006.

PIRES, F. da S.; KUAN, G.S.S. Máquina de Papel. In : PHILIPP, P.; D’ALMEIDA M.L.O. (Ed.). Celulose e Papel - Tecnologia da fabricação da pasta celulósica. 2. ed. São Paulo: IPT/SENAI, 1988. v.2, p. 657-742.

PURCHIO, A.; GAMBALE, W.; PAULA, C.R. Airborne fungi of baixada Santista, State of São Paulo. Revista Microbiologia, v.15, n.4, p.258-265, 1984.

RAKOTONIRAINY, M.S.; HEUDE, E.; LAVÉDRINE, B. Isolation and attempts of biomolecular characterization of fungal strains associated to foxing on a $19^{\text {th }}$ century book. Journal of Cultural Heritage, v 8, n.2, p.126-133, 2007. 
RAKOTONIRAINY, M.S.; LAVÉDRINE, B. Screening for antifungal activity of essential oils and related compounds to control the biocontamination in libraries and archives storage areas. International Biodeterioration \& Biodegradation, v.55, n.2, p.141-147, 2005.

REYNOLDS, S.J.; STREIFEL, A.J.; McJILTON, C.E. Elevated airbourne concentrations of fungi in residential and office environments. American Industrial Hygiene Association Journal, v.51, n.11, p.601-604, 1990.

ROSA, H.; LEMOS, J.A.; COSTA, C.R.; SILVA, M. do R.R.; FERNANDES, O. de F.L. Ocorrência de fungos filamentosos em acervo da Faculdade de Medicina da Universidade Federal de Goiás. Revista de Patologia Tropical, v.37, n.1, p.65-69, 2008.

SARANTOPOUlOU, E.; SAMARDZIJA, Z.; KOBE, S., KOLLIA, Z.; CEFALAS, A.C. Removing foxing stains from old paper at 157nm. Applied Surface Science, v. 208/209, p.311316, 2003.

SCOTT, G. Formação de mofo em ambientes tropicais: discussão. In: MENDES, M.; DA SILVEIRA, L.; BEVILAQUA, F.; BAPTISTA, A.C.N. (Org.). Conservação - Conceitos e práticas. Tradução de Vera Ribeiro. Rio de janeiro: UFRJ, 2001, p.261-278.

SHIRAKAWA, M.A.; AIHARA, E.Y.; DIAS, C.M.R.; GAYLARD, C.C.; JOHN, V.M. Fungal colonization on fiber cement exposed to the elements in a tropical climate. In: DBMC INTERNATIONAL CONFERENCE ON DURABILITY OF BUILDING MATERIALS AND COMPONENTS, 11., 2008, Istanbul, Turkey. Proceedings... Istanbul: DBMC, 2008. v.1. p.229-236.

SHIRAKAWA, M.A.; BEECH, I.B.; TAPPER, R.; CINCOTTO, M.A.; GAMBALE, W. The development of a method to evaluate bioreceptivity of indoor mortar plastering to fungal growth. International Biodeterioration and Biodegradation, n. 51, p.83-92, 2003.

SHIRAKAWA, M.A. Biodeterioração de argamassas por fungos - Desenvolvimento de teste acelerado para avaliação da biorreceptividade. $139 \mathrm{f}$. Tese (Doutorado em Microbiologia) Instituto de Ciências Biomédicas, Universidade de São Paulo, São Paulo, 1999.

SINGH, J. The built environment and the development of fungi. In: (Ed.) Building Mycology - management of decay and health in buildings. London: Chapman \& Hall, 1994. p. $1-21$.

SZCZEPANOWSKA, H. Biodeterioration of art objects on paper. Journal of the Institute of Paper Conservation, v.10, p. 31-39, 1986.

SZCZEPANOWSKA, H.; LOVETT, C.M. A study of the removal and prevention of fungal stain on paper. Journal of the Americam Institute for Conservation, v.31, n.2. p. 147-160, 1992.

TECHNICAL ASSOCIATION OF THE PULP AND PAPER INDUSTRY. Fungus resistance of paper and paperboard -T 487 pm-99. United State of America: TAPPI, 1999. 
VASIL'CHENKO, L.G.; KHROMONYGINA, V.V.; KARAPETYAN, K.N.; VASILENKO, O.V.; RABINOVICH, M.L. Cellobiose dehydrogenase formation by filamentous fungus Chaetomium sp. INBI 2-26(-). Journal of Biotechnology, v.119, p. 44-59, 2005.

WINSTON, P.W.; BATES, D.H. Saturated solutions for the control of humidity in biological research. Ecology, v.41, n.1, p. 232-7, 1960.

YANG, C.S.; JOHANNING, E. Airborne fungi and mycotoxins. In: HURST, C.J.; KNUDSEN, G.R.; MCINESNEY, M.J.; STETZENBACH, L.D.; WALTER, M.V. (Ed.). Manual of environmental Microbiology. Washington, D.C: American Society for Microbiology, 1997. p. 651-660.

WU, P.-C.; LI, Y.-Y.; CHIANG, C.-M.; HUANG, C.-Y.; LEE, C.-C.; LI, F.-C.; SU, H.-J. Changing microbial concentrations are associated with ventilation performance in Taiwan's airconditioned office buildings. Indoor Air, v.15, n.1, p. 19-26, 2005.

ZOTTI, M.; FERRONI, A.; CALVINI, P. Microfungal biodeterioration of historic paper: Preliminary FTIR and microbiological analyses. International Biodeterioration and Biodegradation, v.62, n.2, p.186-194, 2008.

ZYSKA, B. Fungi Isolated from Library Materials: A review of the Literature. International Biodeterioration and Biodegradation, n.40, n.1, p. 43-51, 1997. 